\title{
Examination of anticipated chemical shift and shape distortion effect on materials commonly used in prosthetic socket fabrication when measured using MRI: A validation study
}

\author{
Mohammad Reza Safari, PhD; ${ }^{1-2 *}$ Philip Rowe, PhD; ${ }^{2}$ Arjan Buis, PhD $^{\mathbf{2}}$ \\ ${ }^{1}$ Department of Orthotics and Prosthetics, University of Social Welfare and Rehabilitation Sciences, Tehran, Iran; \\ ${ }^{2}$ Department of Bioengineering, University of Strathclyde, Glasgow, United Kingdom
}

\begin{abstract}
The quality of lower-limb prosthetic socket fit is influenced by shape and volume consistency during the residual limb shape-capturing process (i.e., casting). Casting can be quantified with magnetic resonance imaging (MRI) technology. However, chemical shift artifact and image distortion may influence the accuracy of MRI when common socket/casting materials are used. We used a purpose-designed rig to examine seven different materials commonly used in socket fabrication during exposure to MRI. The rig incorporated glass marker tubes filled with water doped with $1 \mathrm{~g} / \mathrm{L}$ copper sulfate (CS) and 9 plastic sample vials (film containers) to hold the specific material specimens. The specimens were scanned 9 times in different configurations. The absolute mean difference of the glass marker tube length was $1.39 \mathrm{~mm}$ (2.98\%) (minimum $=0.13 \mathrm{~mm}$ [0.30\%], maximum $=5.47 \mathrm{~mm}$ [14.03\%], standard deviation $=0.89 \mathrm{~mm}$ ). The absolute shift for all materials was $<1.7 \mathrm{~mm}$. This was less than the measurement tolerance of $+/-2.18 \mathrm{~mm}$ based on voxel (three-dimensional pixel) dimensions. The results show that MRI is an accurate and repeatable method for dimensional measurement when using matter containing water. Additionally, silicone and plaster of paris plus $1 \mathrm{~g} / \mathrm{L} \mathrm{CS}$ do not show a significant shape distortion nor do they interfere with the MRI image of the residual limb.
\end{abstract}

Key words: accuracy, casting, chemical shift, MRI, prosthesis, prosthetic socket, residual limb, residual limb volume, shape distortion, socket material.

\section{INTRODUCTION}

The purpose of the prosthetic socket is to provide a mechanical coupling between a residual limb and a prosthesis. The overall success of the prosthesis is influenced by the quality of this coupling. Socket fit is the most important characteristic of a prosthesis as indicated by users [1-3]. State of the art prosthetic sockets are designed and hand-crafted for the individual, and the socket is usually made through the process of shape capturing, rectification, and alignment.

Depending on the socket concept, a plaster of paris (POP) wrap cast is manually applied over the residual limb (residuum) or over the elastomeric liner covering

Abbreviations: $3-\mathrm{D}=$ three-dimensional, $\mathrm{ANOVA}=$ analysis of variance, $\mathrm{CI}=$ confidence interval, $\mathrm{CS}=$ copper sulfate, $\mathrm{CT}=$ computed tomography, MRI = magnetic resonance imaging, $\mathrm{POP}=$ plaster of paris, $\mathrm{RF}=$ resonance frequency, $\mathrm{SD}=$ standard deviation, $\mathrm{SXCT}=$ spiral X-ray computer tomography, TI = tolerance interval.

*Address all correspondence to Mohammad Reza Safari, PhD; Department of Orthotics and Prosthetics, University of Social Welfare and Rehabilitation Sciences, Tehran, Iran 1985713834; +98(0)21-2218-0010.

Email: mo.safari@uswr.ac.ir

http://dx.doi.org/10.1682/JRRD.2011.09.0159 
the residual limb with the aim of capturing a modified shape of the soft tissues. This shape is used to produce a positive model, which is afterward adapted (rectified) according to one of a number of design paradigms. The performance of an individual prosthetist is strongly influenced by personal experience, skill, and beliefs [4-5]; hence these procedures are often inconsistent.

The shape-capturing consistency of hands-on (patellar tendon bearing) and hands-off (ICECAST Compact ${ }^{\circledR}$, Össur; Reykjavik, Iceland) sockets has been compared using a manikin model [4]. It was shown that the hands-off concept has more consistent results than the hands-on socket for shape capturing. The hands-on concept had a maximum radius variation of approximately $2.4 \mathrm{~mm}$ in the distal part and $5 \mathrm{~mm}$ in the proximal part of the residual limb, whereas the hands-off concept revealed a constant pattern of maximum radius variation of $1.4 \mathrm{~mm}$ along the length of the model in both distal and proximal parts.

Quantification of inter- and intrasocket shape and volume differences requires accurately aligning a threedimensional (3-D) model of the residual limb in a common coordinate system. Optical scanning, including laser scanning, is the most commonly used method to construct the 3-D model of the residual limb. Attempts have been made to align the 3-D model using minimized volume difference [5], anatomical landmarks [6], feature-extraction techniques [7], line of best fit through the centroids of the cross-sections [8], and weighted mean absolute difference in combination with the alignment of surface normals [9].

In surface scanning methods, the morphological information about the bone and its relation to the surface of the socket, which could be useful in better understanding of the socket fit, is missing. Spiral X-ray computer tomography (SXCT), magnetic resonance imaging (MRI), and ultrasound provide both internal and external limb information. Therefore, the rigid internal limb structure (e.g., tibia) can be used as a reference to align multiple 3-D models of a residual limb [10-11]. These methods can be used to scan the residual limb while the socket/prosthesis is manufactured [12]. Smith et al. obtained two SXCT scans of seven transtibial residual limbs for each of two sessions [11]. The tibia was segmented from the SXCT scans with Analyze ${ }^{\circledR}$ software (AnalyzeDirect, Inc; Overland Park, Kansas) and then used to register all inter- and intrasession scans to a common coordinate system. The results of their study showed that this registration technique has an error of approximately 1 percent relative to the mean volume of the residual limb [11].
From a two-dimensional transverse slice sequence, computed tomography (CT) can provide a 3-D model of the residual limb. Data from CT have been used in computer-assisted design systems [13] as well as in finite element studies [14-16]. Soft tissue and bone can be extracted from SXCT with a resolution better than $1 \mathrm{~mm}$ and accuracy of $2.2 \mathrm{~mm}$ [17-18]. However, CT technology should be used with caution because of ionizing radiation, which is of special concern after repeated measurements.

MRI is a nonionizing, high-resolution imaging technique that can provide a clear distinction between tissues. Studies have shown that MRI is an accurate method of soft tissue and bone dimension measurement and volume assessment, and it has been used to estimate accurate morphological information of different tissues, e.g., bone, muscle, and articular cartilage [19-26].

The so-called chemical and mechanical shifts are the main issues that may influence the accuracy and validity of a scanned MRI image of a residual limb. Mechanical shift is caused by a physical disturbance, such as the movement of the segment of interest during the scanning procedure. Chemical shift is a result of the chemical properties of materials inside the magnetic field. The spin of a nucleus in a magnetic field depends on the magnetic field of the molecular environment. The total magnetic field experienced by a nucleus is the sum of the magnetic fields of the scanner and the local magnetic fields resulting from electron movement around the nucleus in its orbit. Therefore, different numbers of electrons cause different amounts of local magnetic fields at each nucleus, which is reflected in the resonance frequency (RF). This variation in RF causes spatial misregistration of material in the frequency-encoding direction. In the human body, water and fat are the source of hydrogen nuclei. Since each of these materials has a different molecular composition, their manifestation in the image is dissimilar. Buis et al. showed in a pilot study that POP and silicone did not distort or interfere with the MRI image [10]. The chemical shift artifact of a particular material is always in one direction relative to the field and with the same magnitude. It can therefore, in principle, be compensated for [10].

Subcutaneous fat is a major part of the lower limb. The accuracy of soft tissue dimensional measurement can be affected by chemical shift resulting from fat and adipose tissue. The residual limb is normally wrapped with casting material in order to prevent soft tissue distortion due to gravitational forces during scanning. However, the shape can be distorted when common casting materials are used if they produce a chemical shift in MRI images. 
The shifted image of the skin can, for example, end up superimposed on adjacent casting materials, influencing the accuracy of the soft tissue boundary detection. Prior to use of MRI in volume and shape quantification of the residual limb, the question of whether there are any artifacts as a direct result of commonly used casting materials needs to be answered.

In addition, the accuracy and repeatability of MRI geometric measurements can be affected by factors such as subject positioning and movement inside the scanner (mechanical shift) and operator-dependent interactions during acquisition and image processing. Therefore, prior to examining possible image artifacts caused by chemical shift, we examined the spatial accuracy and repeatability of MRI.

\section{METHODS}

Specimens of seven different common prosthetic casting materials used in transtibial socket fabrication, including silicone, silicone gel, polyurethane, polypropylene, Pe-lite (closed cell foam), laminate, and POP, were assessed for possible shape distortion and chemical shift.

Relevant materials were fitted in plastic film containers (diameter $30 \mathrm{~mm}$ ) and then labeled from 1 to 9, creating 3 rows and 3 columns. We filled 3 containers with wet POP bandage, each doped with different concentrations of copper sulfate (CS), namely $1 \mathrm{~g} / \mathrm{L}, 2 \mathrm{~g} / \mathrm{L}$, and $3 \mathrm{~g} / \mathrm{L}$, to investigate differences in signal intensity. The POP was placed inside the containers. Excess water was drained and the sample was left to cure. The laminate specimens were made out of acrylic resin (matrix) and layers of perlon stockinette, carbon fiber, and glass fibers. The materials were prepared and filled in the containers a few days before scanning, except for the POP, which was prepared and placed inside the containers just 10 min before scanning so that it was cured but remained wet.

An acrylic glass (Perspex ${ }^{\mathrm{TM}}$, Lucite International; Hampshire, United Kingdom) rig $(300 \times 160 \mathrm{~mm})$ was purpose-designed and produced to hold the containers within the bore of the MRI scanner (Figure 1). Perspex is a material that has the same magnetic susceptibility as water, which eliminates the susceptibility artifact [27] and so does not distort the image. Three rows of three holes were made on the plate with the same diameter as the exterior diameter of the containers. Containers passed through the holes and were suspended using the larger diameter of the cap and without any movement of relevance.
Three sets of glass tubes (length $100 \mathrm{~mm} \times$ diameter $5 \mathrm{~mm}$ ) filled with water (doped with $1 \mathrm{~g} / \mathrm{L} \mathrm{CS}$ ) were placed on the plate perpendicular to each other next to each row of containers. Six recesses were made so that the marker tubes could be positioned accurately. Additionally, three holes were made to fit marker tubes perpendicular to the plate. The marker tubes were placed in the holes and recesses and secured with a drop of superglue. These markers were used to evaluate the accuracy and repeatability of MRI dimension measurement in three orthogonal directions and as reference markers for examining possible image distortion of socket materials.

All the holes and recesses were made using a validated computer numerical control milling machine (model FP4NC, Deckel; Pfronten, Germany). The accuracy and validity of the machine was tested [28], and it was reported to have an accuracy of $0.005 \mathrm{~mm}$. In order to keep the plate steady inside the bore of the MRI machine during scanning, a Perspex cylinder (length $326 \mathrm{~mm} \times$ diameter $172 \mathrm{~mm}$ ) was used (Figure 1). This also helped with locating the plate inside the scanner. Specimens were subsequently scanned 9 times. After each scan, the cylinder was removed from the bore of the machine and all containers (containing the socket materials) were shuffled around so that all materials were scanned in all 9 locations, giving data across the field of view of the MRI. To be consistent, we placed the Perspex cylinder into the scanner the same way each time, with position 1 entered first into the bore of the scanner (Figure 1). This also made it possible to consistently match the coordinate system in the image volumes to that of the scanner. A fast-spoiled gradient-recalled-echo (FSPGR) pulse sequence with the following parameters was adopted: field intensity 3T, repetition time $6.9 \mathrm{~s}$, time of echo $1.5 \mathrm{~s}$, inversion time $500 \mathrm{~ms}$, bandwidth $31.25 \mathrm{KHz}$, flip angle $12^{\circ}$, matrix $256 \times 256$, slice thickness $1.8 \mathrm{~mm}$, voxel dimensions $1.8 \times 1.09 \times 1.09 \mathrm{~mm}$, and signal average 1.

Data were exported to state-of-the-art visualization software (Analyze ${ }^{\circledR}$ ) developed at the Mayo Clinic Biomedical Imaging Resource in Rochester, Minnesota. All files were downloaded as a separate volume in the main workspace of the software. The voxel dimensions were resized to an isotropic dimension (voxels $1.09 \times 1.09 \times$ $1.09 \mathrm{~mm}$ ) so that the volume was the same size as the real-life specimen. Additionally, using the reference marker tubes, we aligned the coordinate system of all the images and matched it to the coordinate system of the scanner. To do this, we downloaded each image to the 


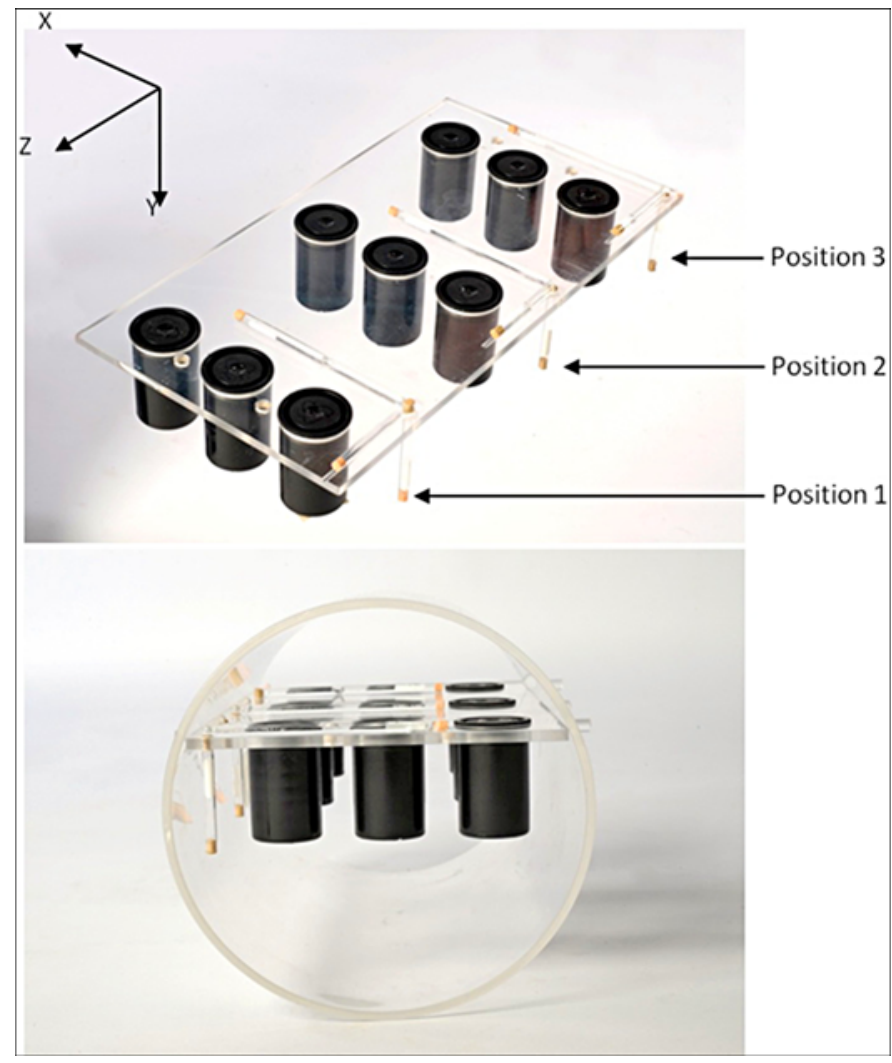

Figure 1.

Experimental scanning setup. Perspex tube enclosing Perspex plate that holds glass tubes and materials containers during scanning.

software workspace and aligned it three times, once for each orthogonal direction. This enabled us to compensate for the effect of possible tilting of the containers during imaging. It was found that three material specimens, polypropylene, Pe-lite, and laminate, were not visible in the images (Figure 2).

The lengths of all the marker tubes in all 3 orthogonal planes in 3 consecutive slices were measured in all 9 scans. Then, distances from the center of the materials to the coordinate system origin, defined by the perpendicular reference markers, were measured in 3 slices: first, middle, and last slice, to check for the possible shift in the location of materials in each $x, y$, and $z$ direction. The coordinate system was set in each slice according to the image direction in the MRI bore (Figure 1 and Figure 2). Additionally, diameters of the materials were calculated from measurements to examine possible image distortion. Finally, the difference between MRI-derived mea-

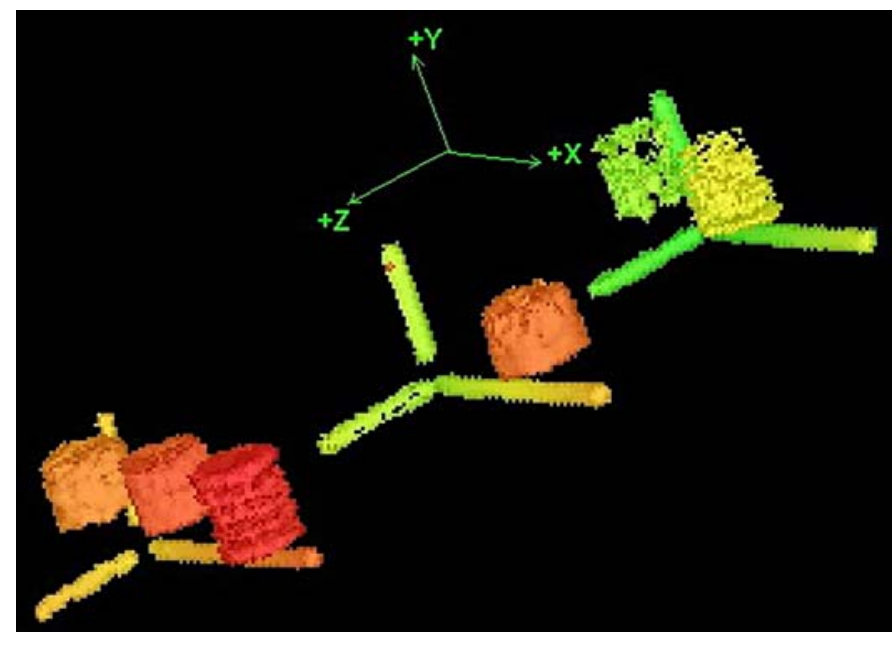

Figure 2.

Three-dimensional chromo-depth volume render of materials.

surements and actual values for all variables was calculated for the statistical analysis.

The alpha level was set at 0.05 . The factorial analysis of variance (ANOVA) test was used to test the effect of scan, slice, direction, and position factors on means of measurement differences. We created interaction plots and performed post hoc comparisons with Bonferroni honest significant difference correction to determine which pairs of the population mean differed once a significant difference was detected. The confidence interval (CI) and tolerance interval (TI) were also calculated. Due to voxel size and a phenomenon called "partial volume effect," the tolerance of measurements in each of the $x, y$, and $z$ directions was measured to be $\pm 2.18 \mathrm{~mm}$. The TI was calculated as the actual value plus/minus the tolerance of measurement. The CI produces a range of values within which the sample mean lies in 95 percent of samples. If the CI of the MRI measurements falls within the TI, the MRI measurements and the actual values are statically significant equivalent [29-30]. The Bland and Altman plot was also created when appropriate [31]. For all tests and plots, we used SPSS version 17.0 (IBM; Armonk, New York).

\section{RESULTS}

Results show that the mean absolute difference of the reference tube length was $1.39 \mathrm{~mm}$ (2.98\%) $($ minimum $=$ $0.13 \mathrm{~mm}[0.30 \%]$, maximum $=5.47 \mathrm{~mm}$ [14.03\%], standard 
deviation $[\mathrm{SD}]=0.89$ ). There was no significant effect of the aforementioned factors on the mean difference of tube length measurements. However, a significant result was found for slice-position interaction $(p<0.02)$. The three positions are shown in Figure 1. The slice-position interaction plot shows that the mean difference is slightly higher in position 1 and stays fairly constant in positions 2 and 3 for slices 1 and 2. Slice 3 follows the reverse pattern, which has a higher mean value in position 3 . In the plots, the mean and upper and lower tolerance limit lines were plotted to show visually whether the means of variables lie within the tolerance limit. It shows that all means lie within the tolerance limit of measurements (Figure 3).

Differences between MRI values and actual values for the distance from the center of each material to the origin of measurement ( $x, y$, and $z$ reference axis) were calculated. The statistical significance of the possible effect of the factors on the mean difference of material distance shows a significant effect of direction factor on the distance measurement $(p<0.001)$. The post hoc test shows that there is no significant difference between mean difference in the $x$ and $z$ directions (mean difference $-0.15 \mathrm{~mm}$, $95 \%$ CI, -0.43 to 0.13 ), whereas mean difference in the $y$ direction is significantly different from that of both $x$ (mean difference $-1.5 \mathrm{~mm}, 95 \% \mathrm{CI},-1.78$ to -1.22 ) and $z$ (mean difference $-1.34 \mathrm{~mm}, 95 \% \mathrm{CI},-1.62$ to -1.06 ) directions.

The material-direction interaction plot shows that materials were shifted on average $1.34 \mathrm{~mm}$ in the positive $y$ direction. Furthermore, it shows that all POP material has similar variability in mean difference and differs from elastomeric materials. Polyurethane has a constant mean difference for both the $x$ and $z$ directions and increases in the $y$ direction. However, mean differences for all materials lie within the tolerance limit of measurements (Figure 4).

The statistical significance of the possible effect of different levels of factors on mean diameter from factorial ANOVA shows that no significant effect exists of scan, slice, direction, or position factors on the mean of diameter measurements.

All CI values for the length of the reference markers fall within the TI (Table). The Bland and Altman plots were created for the distance of the materials (Appendix, available online only). Additionally, CIs of the diameter of all the materials in both the $x$ and $z$ directions versus the TI (Table) show that the diameter of silicone and $\mathrm{POP}+1 \mathrm{~g} / \mathrm{L}$ CS do not differ from the actual value in the $z$ direction, and in the $x$ direction, the CI of silicone and

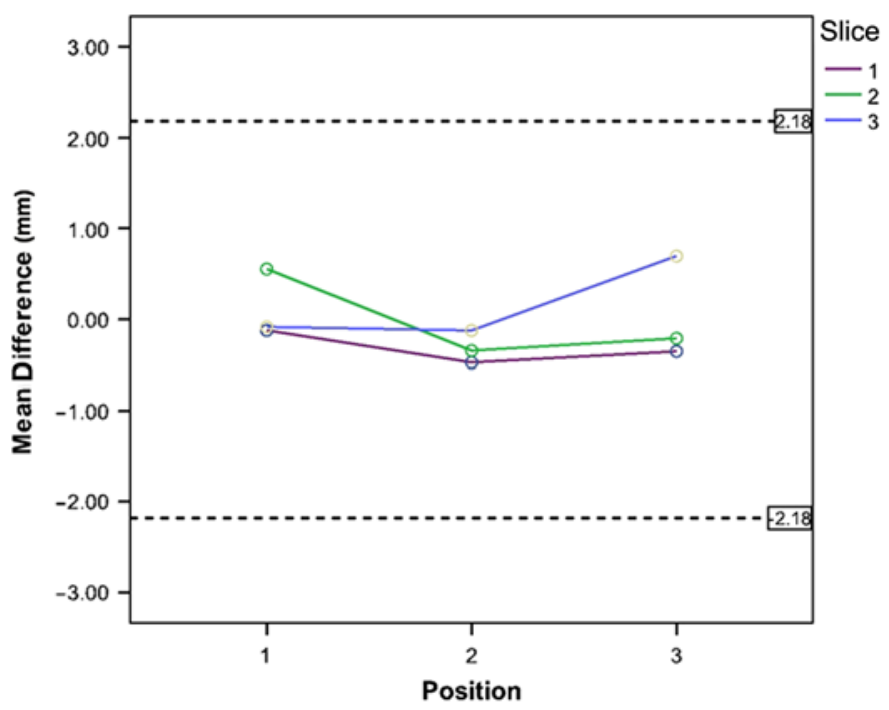

Figure 3.

Slice-position interaction plot for mean difference of tube length. Dotted horizontal lines represent tolerance interval.

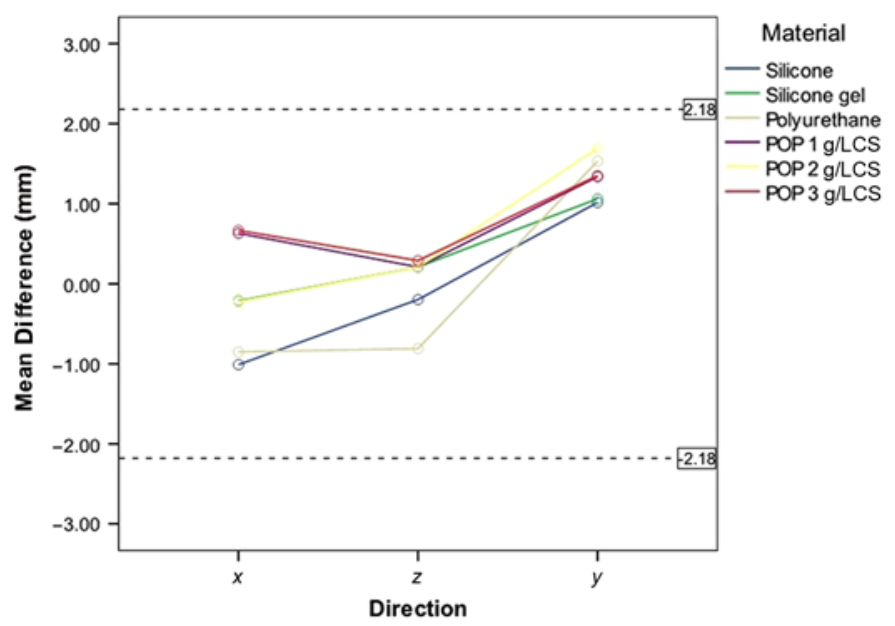

Figure 4.

Direction-material interaction plot for mean distance difference. Dotted horizontal lines represent tolerance interval. CS = copper sulfate, $\mathrm{POP}=$ plaster of paris.

all three different CS-concentrated POP samples remain within the TI (Table).

\section{DISCUSSION}

The purpose of this study was to examine the anticipated chemical shift artifact and shape distortion of common 
Table.

Confidence interval (CI) and tolerance interval (TI) for length of reference markers and diameter of materials in $x, z$, and $y$ directions. Diameter of materials measurement in $y$ direction was not applicable.

\begin{tabular}{|c|c|c|c|c|c|c|}
\hline Direction & Material & CI/TI & Mean (mm) & Upper Limit & Lower Limit & SD/Tolerance \\
\hline \multirow[t]{10}{*}{$\bar{x}$} & Tube Length & CI & 93.21 & 93.52 & 93.04 & 1.23 \\
\hline & & TI & 93.42 & 95.60 & 91.24 & 2.18 \\
\hline & Silicone & CI & 28.83 & 29.23 & 28.42 & 1.01 \\
\hline & Silicone Gel & CI & 28.07 & 29.04 & 27.09 & 2.46 \\
\hline & & TI & 30.00 & 32.18 & 27.82 & 2.18 \\
\hline & $\mathrm{POP}+1 \mathrm{~g} / \mathrm{L} \mathrm{CS}$ & CI & 30.18 & 30.69 & 29.67 & 1.28 \\
\hline & & TI & 30.00 & 32.18 & 27.82 & 2.18 \\
\hline & $\mathrm{POP}+2 \mathrm{~g} / \mathrm{L} \mathrm{CS}$ & CI & 30.66 & 31.28 & 30.05 & 1.56 \\
\hline & & TI & 30.00 & 32.18 & 27.82 & 2.18 \\
\hline & $\mathrm{POP}+3 \mathrm{~g} / \mathrm{L} \mathrm{CS}$ & CI & 30.70 & 31.18 & 30.22 & 1.21 \\
\hline & Silicone & CI & 30.06 & 30.48 & 29.64 & 1.06 \\
\hline & & TI & 30.00 & 32.18 & 27.82 & 2.18 \\
\hline & Silicone Gel & CI & 28.15 & 28.72 & 27.57 & 2.46 \\
\hline & & TI & 30.00 & 32.18 & 27.82 & 2.18 \\
\hline & Polyurethane & CI & 29.32 & 29.96 & 28.69 & 1.6 \\
\hline & & TI & 30.00 & 32.18 & 27.82 & 2.18 \\
\hline & $\mathrm{POP}+1 \mathrm{~g} / \mathrm{L} \mathrm{CS}$ & CI & 30.42 & 30.97 & 29.88 & 1.35 \\
\hline & & $\mathrm{TI}$ & 30.00 & 32.18 & 27.82 & 2.18 \\
\hline & $\mathrm{POP}+2 \mathrm{~g} / \mathrm{L} \mathrm{CS}$ & CI & 31.11 & 31.64 & 30.58 & 1.33 \\
\hline & & TI & 30.00 & 32.18 & 27.82 & 2.18 \\
\hline & $\mathrm{POP}+3 \mathrm{~g} / \mathrm{L} \mathrm{CS}$ & CI & 30.99 & 31.65 & 30.34 & 1.65 \\
\hline
\end{tabular}

prosthetic materials and their effect on MRI images. A purpose-designed Perspex rig incorporating a reference coordinate system using glass marker tubes filled with water doped with $1 \mathrm{~g} / \mathrm{L}$ CS was validated prior to material specimen scans.

Mitsiopoulos et al. examined the validity of volume estimates by MRI using two phantoms filled with paramagnetic solution [24]. MRI scanning included 16 images of $10 \mathrm{~mm}$ spacing and 7 images of $40 \mathrm{~mm}$ spacing. MRI and actual value (derived from a volumetric flask) difference was about 3.0 percent for phantom one and $<2.6$ percent for phantom two [24]. They indicated that when spacing between slices was between 10 and $40 \mathrm{~mm}$, volume can be measured with an error $<1$ percent. The mean absolute difference in the current study is similar to the percentage difference in the study by Mitsiopoulos et al. [24]. However, in the phantom study by Mitsiopoulos et al., the slice spacing was bigger than in our experiment: 10 and $40 \mathrm{~mm}$ compared with $1.8 \mathrm{~mm}$. The measurement error, one would imagine, should increase as a result of larger slice spacing. However, this could not be confirmed by comparing the results of our study with those of Mitsiopoulos et al. [24]. In our study, just the lengths of the tubes were measured, whereas in Mitsiopolous et al.'s, study volume measurements were performed because the accuracy of volume measurements of their phantoms could be influenced by other factors (e.g., the cross-sectional area of the slices or shape of the phantom) [24]. 
Ross et al. measured mean cross-sectional areas of polyvinyl tubes filled with peanut oil in MRI images and then compared them with the actual values [32]. They reported an error of 0.6 percent, with a range from 0.1 to 1.5 percent. The mean error in their study was less than that found in the current study (0.6\% vs $2.98 \%)$. However, in their study, the cross-sectional area was measured as opposed to the length measurement in our study.

In the study by Byrum et al., the accuracy of MRI volumetric measurement was examined using a $17 \mathrm{~cm}$ spherical phantom filled with water that was doped with a gadolinium-based contrast agent as well as a complex anatomically realistic phantom. The complex phantom, made of layers of plastic, was filled with fluid to produce contrast [33]. They reported an error of 3 percent for the spherical phantom and 2.5 to 5 percent error for the complex phantom volume measurement. The relatively higher error in their study for the complex phantom compared with our study (2.98\%) is possibly due to a greater segmentation process error in their data. In all the aforementioned studies, the MRI volume and/or surface area measurements of the phantoms were compared with actual values, whereas in the current study, the distance measurement was validated. One would expect the MRI error would be different for surface area and volume measurement because of the partial volume effect and the employed segmentation method.

The measurement error on repeated scanning could result from variability in scanner image acquisition or intrarater inconsistency. The results suggest that the scanrescan reproducibility is high. The effect of different levels of scan factor (9 scans) on the mean difference of tube length measurement was not significant $(p>0.05)$. In examining the interscan reproducibility of carotid morphology measurement in 18 individuals, $\mathrm{Li}$ et al. found no significant difference between repeated scans $(p>$ 0.05 ) [34]. Furthermore, for the total body adipose tissue measurement of three rats, researchers found $0.02 \mathrm{~cm}^{2} \pm$ $0.9 \mathrm{~cm}^{2}$ (mean $\pm \mathrm{SD}$ ) difference in two consecutive MRI scans when the animals were not removed between trials [32]. In our study, scan 4 had the minimum absolute mean difference (mean $\pm \mathrm{SD}=0.004 \mathrm{~mm} \pm 1.864 \mathrm{~mm}$ ), and the maximum absolute mean difference was for scan 7 (mean $\pm \mathrm{SD}=0.512 \mathrm{~mm} \pm 1.620 \mathrm{~mm}$ ).

This experiment was conducted because of concerns about MRI artifacts, namely chemical shift, resulting from common socket materials. This shift can occur as a result of differences in RF of the nuclei in different molecular environments because they are exposed to different amounts of magnetic field. This variation in RF causes spatial misregistration of material in the frequency encoding direction. The processing frequencies of silicone (breast implant), water, and fat have been measured using proton MRI spectroscopy as 2,175, 2,550, and 2,250 $\mathrm{Hz}$, respectively [35]. Almost the same results were found for spectroscopic analysis of frequency difference between water, lard, and silicone vitreous ocular implant [36]. The results showed $220 \mathrm{~Hz}$ frequency difference between water and lard and $80 \mathrm{~Hz}$ frequency difference between lard and silicone.

Previous research has reported a chemical shift artifact on T1-weighted, T2-weighted, and proton-density MRI images of breast silicone implant phantoms [35]. It was shown that the chemical shift artifact on T1weighted MRI images was minimal relative to the T2weighted images. In a phantom study of silicone fluid polymer and silicone lubrication oil, Bash et al. found chemical shift on both T1-weighted and T2-weighted images, with more prominence on the T2-weighted image [36]. The amount of chemical shift depends on the magnetic field strength and the selection of pulse sequence bandwidth [36-37]. Chemical shift may increase by increasing the magnetic field strength and decreasing the sequence bandwidth.

In this study, the measured chemical shift of silicone was $-1.010,-0.197$, and $1.015 \mathrm{~mm}$ in the $x, z$, and $y$ directions, respectively. The silicone gel showed $x=-0.214$, $z=0.210$, and $y=1.060 \mathrm{~mm}$ chemical shift, and for polyurethane, the shift was $-0.850,-0.809$, and $1.531 \mathrm{~mm}$ in the $x, z$, and $y$ directions, respectively. The absolute shifting for all material including different CS-concentrated POP was $<1.7 \mathrm{~mm}$. This was not significant considering the measurement tolerance of $\pm 2.18 \mathrm{~mm}$. This is in agreement with a pilot study by Buis et al. in which no detectable chemical shift of silicone (used for prosthetic liners) was reported [10].

Diameter of POP with all three different concentrations of CS was slightly overestimated by MRI in both the $x$ and $z$ directions. The overestimation was worse for POP with higher amounts of CS (2 g/L and $3 \mathrm{~g} / \mathrm{L})$ because the signal intensity increases as more contrast agent is used. This results in overprojection of the section thickness, i.e., more voxels light up at the boundary of the object [38]. Silicone gel diameter was underestimated in MRI in both the $x$ and $y$ directions, and polyurethane diameter was underestimated in the $y$ direction but 
overestimated in the $x$ direction. The silicone showed an underestimated diameter measurement in the $x$ direction; however, the diameter measurement was within the tolerance limit with a relatively small SD. This shows there is no significant over- or underprojection of the silicone (Table). The residual limb is normally surrounded with casting materials (e.g., POP or silicone) during MRI scanning. The measured chemical shift artifact from casting materials could jeopardize residual limb boundary detection when constructing the 3-D model; the image of the casting material could superimpose onto the image of underlying soft tissue. However, knowing the amount of chemical shift resulting from a casting material, one can compensate for the artifact. A possible solution would be to prevent images of casting material from superimposing onto images of the residual limb by increasing the gap between the residual limb and the surrounding material with some form of MRI-opaque material.

In order to identify the proper time for permanent prosthetic fitting, Lilja and Oberg measured postamputation volume fluctuation of the residual limb with laser scanning. Based on experiences of amputees, they assumed "bad fit" criteria to be one or two layers of socks required over the residual limb; i.e., if use of one or two socks was required by the amputee, then a new socket must be made. They measured the percentage volume of one and two socks over the residual limb as 5.2 percent and 9.4 percent, respectively [39]. Their results for sock volume percentage are in agreement with those of Fernie and Holliday [40]. Additionally, postoperative residual limb volume change has been reported to be up to 35 percent [12], and diurnal volume change is on the order of 2 percent [41]. Sanders et al. calculated a uniform volume change of 5 percent in a limb with $90 \mathrm{~mm}$ diameter would be $1 \mathrm{~mm}$ change in diameter [42]. Because of the CI of $2.18 \mathrm{~mm}$ for diameter measurements, the scanning method presented in this study would possibly be best for postoperative application. However, Sanders et al. noted that for devices used for scanning the residual limb, the volume resolution (in percentage) is different from the dimensional resolution (in millimeters); the volume error is more forgiving [12]. Therefore, we suggest testing the accuracy of MRI in residual limb volume measurements.

MRI is a nonionizing imaging method that is superior to surface scanning methods. It can provide information on residual limb internal structure, e.g., bone and muscle. It would be helpful to relate this information to the surface of the socket for better understanding of residual limb-socket interaction. This study examined the MRI image artifact resulting from different casting materials; we found that MRI of silicone and POP $+1 \mathrm{~g} / \mathrm{L} \mathrm{CS}$ were fit for use in prosthetic socket manufacture. Future work should examine the accuracy of MRI in soft tissue morphological measurement while the residual limb is surrounded with casting material.

\section{CONCLUSIONS}

The tolerance of measurement in this study was $\pm 2.18 \mathrm{~mm}$, defined by the voxel dimension. The SDs of measurements in the $x, y$, and $z$ directions $(1.23,1.26$, and $1.90 \mathrm{~mm}$, respectively) are less than the tolerance limit. The results show that MRI is an accurate and repeatable method of dimensional measurement when using matter containing water. In addition, we found that water-filled tubes can be used as reference landmarks for the purpose of examining chemical shift and shape distortion of socket materials in MRI images.

To enable the quantification of different socket design concepts for research purposes, researchers and prosthetists should be able to identify the boundary between the residual limb (skin) and casting material. We suggest, based on the results of the current study, that silicone and POP +1 g/L CS can be measured accurately and within the tolerance of the voxel dimensions chosen using MRI. The MRI image of these materials will have relatively small overlap with the skin boundary, making detection of the surface boundary relatively easy and segmentation unambiguous. Therefore, the shape and volume of the residual limb, while wrapped with these materials, could be accurately quantified using MRI.

\section{ACKNOWLEDGMENTS}

\section{Author Contributions:}

Study concept and design: M. R. Safari, A. Buis, P. Rowe. Analysis and interpretation of data: M. R. Safari, A. Buis, P. Rowe. Drafting of manuscript: M. R. Safari.

Critical revision of manuscript for important intellectual content: M. R. Safari, A. Buis, P. Rowe.

Statistical analysis: M. R. Safari.

Study supervision: A. Buis, P. Rowe.

Financial Disclosures: The authors have declared that no competing interests exist.

Funding/Support: This material was based on work supported by the Iranian Ministry of Health and Medical Education (grant 38234). 
Additional Contributions: We gratefully acknowledge the NeuroRadiology Department, Institute of Neurological Sciences, Southern General Hospital, Glasgow, Scotland, for their contribution to the MRI work. We would also like to thank Mr. John McLean for taking the MRI images and Dr. Angus McFadyen for advice and assistance in statistical analysis.

\section{REFERENCES}

1. Legro MW, Reiber G, del Aguila M, Ajax MJ, Boone DA, Larsen JA, Smith DG, Sangeorzan B. Issues of importance reported by persons with lower limb amputations and prostheses. J Rehabil Res Dev. 1999;36(3):155-63. [PMID:10659798]

2. Hoaglund FT, Jergesen HE, Wilson L, Lamoreux LW, Roberts R. Evaluation of problems and needs of veteran lowerlimb amputees in the San Francisco Bay Area during the period 1977-1980. J Rehabil Res Dev. 1983;20(1):57-71. [PMID:6887067]

3. Hagberg K, Brånemark R, Hägg O. Questionnaire for Persons with a Transfemoral Amputation (Q-TFA): initial validity and reliability of a new outcome measure. J Rehabil Res Dev. 2004;41(5):695-706. [PMID:15558399] http://dx.doi.org/10.1682/JRRD.2003.11.0167

4. Buis AW, Blair A, Convery P, Sockalingam S, McHugh B. Pilot study: data-capturing consistency of two trans-tibial casting concepts, using a manikin stump model: a comparison between the hands-on PTB and hands-off ICECAST compact concepts. Prosthet Orthot Int. 2003;27(2):100-106. [PMID:14571939] http://dx.doi.org/10.1080/03093640308726665

5. Sidles JA, Boone DA, Harlan JS, Burgess EM. Rectification maps: a new method for describing residual limb and socket shapes. J Prosthet Orthot. 1989;1(3):149-53.

6. Jimenez D, Darm T, Rogers B, Walsh N. Locating anatomical landmarks for prosthetics design using ensemble neural networks. In: Proceedings of International Conference on Neural Networks; 1997 Jun 9-12; Houston, TX. Piscataway (NJ): IEEE; 1997. p. 81-85.

7. Chahande A, Billakanti S, Walsh N. Lower limb shape characterization using feature extraction techniques [noncontact laser scanning]. In: Proceedings of the 16th Annual International Conference of the IEEE, Engineering in Medicine and Biology Society, Engineering Advances: New Opportunities for Biomedical Engineers; 1994 Nov 3-6; Baltimore, MD. Los Alamitos (CA): IEEE; 1994. p. 482-83.

8. Lemaire ED, Johnson F. A quantitative method for comparing and evaluating manual prosthetic socket modifications. IEEE Trans Rehabil Eng. 1996;4(4):303-9.

[PMID:8973956]

http://dx.doi.org/10.1109/86.547931
9. Zachariah SG, Sorenson E, Sanders JE. A method for aligning trans-tibial residual limb shapes so as to identify regions of shape change. IEEE Trans Neural Syst Rehabil Eng. 2005;13(4):551-57. [PMID:16425837] http://dx.doi.org/10.1109/TNSRE.2005.858459

10. Buis AW, Condon B, Brennan D, McHugh B, Hadley D. Magnetic resonance imaging technology in transtibial socket research: a pilot study. J Rehabil Res Dev. 2006; 43(7):883-90. [PMID:17436174] http://dx.doi.org/10.1682/JRRD.2005.08.0145

11. Smith KE, Commean PK, Vannier MW. Residual-limb shape change: three-dimensional CT scan measurement and depiction in vivo. Radiology. 1996;200(3):843-50. [PMID:8756942]

12. Sanders JE, Fatone S. Residual limb volume change: systematic review of measurement and management. J Rehabil Res Dev. 2011;48(8):949-86. [PMID:22068373] http://dx.doi.org/10.1682/JRRD.2010.09.0189

13. Faulkner VW, Walsh NE. Computer designed prosthetic socket from analysis of computed tomography data. J Prosthet Orthot. 1989;1(3):154-64.

14. Zachariah SG, Sanders JE, Turkiyyah GM. Automated hexahedral mesh generation from biomedical image data: applications in limb prosthetics. IEEE Trans Rehabil Eng. 1996;4(2):91-102. [PMID:8798076] http://dx.doi.org/10.1109/86.506406

15. Commean PK, Smith KE, Vannier MW, Szabo BA, Actis RL. Finite element modeling and experimental verification of lower extremity shape change under load. J Biomech. 1997;30(5):531-36. [PMID:9109567] http://dx.doi.org/10.1016/S0021-9290(96)00179-0

16. Shuxian Z, Wanhua Z, Bingheng L. 3D reconstruction of the structure of a residual limb for customising the design of a prosthetic socket. Med Eng Phys. 2005;27(1):67-74. [PMID:15604007] http://dx.doi.org/10.1016/j.medengphy.2004.08.015

17. Commean PK, Smith KE, Cheverud JM, Vannier MW. Precision of surface measurements for below-knee residua. Arch Phys Med Rehabil. 1996;77(5):477-86. [PMID:8629925] http://dx.doi.org/10.1016/S0003-9993(96)90037-4

18. Liu J, Zhang R, Ruan SW. Calibration and analysis of measurement system for surface of the stump. Chinese J Biomed Eng. 1997;16:147-53.

19. Aisen AM, Martel W, Braunstein EM, McMillin KI, Phillips WA, Kling TF. MRI and CT evaluation of primary bone and soft-tissue tumors. AJR. 1986;146(4):749-56. [PMID:3485348]

20. Cyteval C, Thomas E, Picot MC, Derieffy P, Blotman F, Taourel P. Normal vertebral body dimensions: a new measurement method using MRI. Osteoporos Int. 2002;13(6): 468-73. [PMID:12107660] http://dx.doi.org/10.1007/s001980200056 
21. Eckstein F, Sittek H, Milz S, Putz R, Reiser M. The morphology of articular cartilage assessed by magnetic resonance imaging (MRI). Reproducibility and anatomical correlation. Surg Radiol Anat. 1994;16(4):429-38.

[PMID:7725201]

http://dx.doi.org/10.1007/BF01627667

22. Haubner M, Eckstein F, Schnier M, Lösch A, Sittek H, Becker C, Kolem H, Reiser M, Englmeier KH. A noninvasive technique for 3-dimensional assessment of articular cartilage thickness based on MRI. Part 2: Validation using CT arthrography. Magn Reson Imaging. 1997;15(7):805-13. [PMID:9309611] http://dx.doi.org/10.1016/S0730-725X(97)00011-8

23. McGibbon CA. Inter-rater and intra-rater reliability of subchondral bone and cartilage thickness measurement from MRI. Magn Reson Imaging. 2003;21(7):707-14. [PMID:14559334] http://dx.doi.org/10.1016/S0730-725X(03)00107-3

24. Mitsiopoulos N, Baumgartner RN, Heymsfield SB, Lyons W, Gallagher D, Ross R. Cadaver validation of skeletal muscle measurement by magnetic resonance imaging and computerized tomography. J Appl Physiol. 1998;85(1): 115-22. [PMID:9655763]

25. Mortimore IL, Marshall I, Wraith PK, Sellar RJ, Douglas NJ. Neck and total body fat deposition in nonobese and obese patients with sleep apnea compared with that in control subjects. Am J Respir Crit Care Med. 1998;157(1): 280-83. [PMID:9445310]

26. Walton JM, Roberts N, Whitehouse GH. Measurement of the quadriceps femoris muscle using magnetic resonance and ultrasound imaging. Br J Sports Med. 1997;31(1):59-64. [PMID:9132215] http://dx.doi.org/10.1136/bjsm.31.1.59

27. Moerland MA, Beersma R, Bhagwandien R, Wijrdeman HK, Bakker CJ. Analysis and correction of geometric distortions in $1.5 \mathrm{~T}$ magnetic resonance images for use in radiotherapy treatment planning. Phys Med Biol. 1995; 40(10):1651-54. [PMID:8532746] http://dx.doi.org/10.1088/0031-9155/40/10/007

28. Convery P, Buis AW, Wilkie R, Sockalingam S, Blair A, McHugh B. Measurement of the consistency of patellartendon-bearing cast rectification. Prosthet Orthot Int. 2003;27(3):207-13. [PMID:14727701] http://dx.doi.org/10.1080/03093640308726683

29. Wellek S. Testing statistical hypotheses of equivalence. London (UK): Chapman \& Hall/CRC; 2003.

30. Hogg RV. Ledolter J. Applied statistics for engineers and physical scientists. 2nd ed. New York (NY): Macmillan Publishing Company; 1992. p. 472.

31. Bland JM, Altman DG. Statistical methods for assessing agreement between two methods of clinical measurement.
Lancet. 1986;1(8476):307-10. [PMID:2868172]

http://dx.doi.org/10.1016/S0140-6736(86)90837-8

32. Ross R, Léger L, Guardo R, De Guise J, Pike BG. Adipose tissue volume measured by magnetic resonance imaging and computerized tomography in rats. J Appl Physiol. 1991;70(5):2164-72. [PMID:1864799]

33. Byrum CE, MacFall JR, Charles HC, Chitilla VR, Boyko OB, Upchurch L, Smith JS, Rajagopalan P, Passe T, Kim D, Xanthakos S, Ranga K, Krishnan R. Accuracy and reproducibility of brain and tissue volumes using a magnetic resonance segmentation method. Psychiatry Res. 1996;67(3):215-34. [PMID:8912960] http://dx.doi.org/10.1016/0925-4927(96)02790-4

34. Li FY, Yarnykh VL, Hatsukami TS, Chu BC, Balu N, Wang JN, Underhill HR, Zhao X, Smith R, Yuan C. Scan-rescan reproducibility of carotid atherosclerotic plaque morphology and tissue composition measurements using multicontrast MRI at 3T. J Magn Reson Imaging. 2010;31(1):168-76. [PMID:20027584] http://dx.doi.org/10.1002/jmri.22014

35. Steinbach BG, Hiskes SK 2nd, Fitzsimmons JR, Lanier L. Phantom evaluation of imaging modalities for silicone breast implants. Invest Radiol. 1992;27(10):841-46.

[PMID:1399441] http://dx.doi.org/10.1097/00004424-199210000-00015

36. Bash C, Rothman M, Hamet M, Sorce D, Zoarski G, Mihara F, Numaguchi Y. MRI of silicone vitreous ocular implants with phantom correlation. Neuroradiology. 1995; 37(4):313-16. [PMID:7666969] http://dx.doi.org/10.1007/BF00588344

37. Smith AS, Weinstein MA, Hurst GC, DeRemer DR, Cole RA, Duchesneau PM. Intracranial chemical-shift artifacts on MR images of the brain: observations and relation to sampling bandwidth. AJR Am J Roentgenol. 1990;154(6): 1275-83. [PMID:2110742]

38. Gadeberg P, Gundersen HJ, Tågehøj F. How accurate are measurements on MRI? A study on multiple sclerosis using reliable 3D stereological methods. J Magn Reson Imaging. 1999;10(1):72-79. [PMID:10398980] http://dx.doi.org/10.1002/(SICI)1522-2586(199907)10: 1<72::AID-JMRI10>3.0.CO;2-Q

39. Lilja M, Oberg T. International forum: proper time for permanent prosthetic fitting. J Prosthet Orthot. 1997;9(2):90-95.

40. Fernie GR, Holliday PJ. Volume fluctuations in the residual limbs of lower limb amputees. Arch Phys Med Rehabil. 1982;63(4):162-65. [PMID:7082139]

41. Sanders JE, Zachariah SG, Jacobsen AK, Fergason JR. Changes in interface pressures and shear stresses over time on trans-tibial amputee subjects ambulating with prosthetic limbs: comparison of diurnal and six-month differences. J Biomech. 2005;38(8):1566-73. [PMID:15958212] http://dx.doi.org/10.1016/j.jbiomech.2004.08.008 
42. Sanders JE, Mitchell SB, Zachariah SG, Wu K. A digitizer with exceptional accuracy for use in prosthetics research: a technical note. J Rehabil Res Dev. 2003;40(2):191-95. [PMID:15077643]

http://dx.doi.org/10.1682/JRRD.2003.03.0193

Submitted for publication September 4, 2011. Accepted in revised form May 17, 2012.

This article and any supplemental material should be cited as follows:

Safari MR, Rowe P, Buis A. Examination of anticipated chemical shift and shape distortion effect on materials commonly used in prosthetic socket fabrication when measured using MRI: A validation study. J Rehabil Res Dev. 2013;50(1):31-42.

http://dx.doi.org/10.1682/JRRD.2011.09.0159

ResearcherID: Mohammad Reza Safari, PhD: A-79992013; Philip Rowe, PhD: A-8814-2013; Arjan Buis, PhD: A-8118-2013

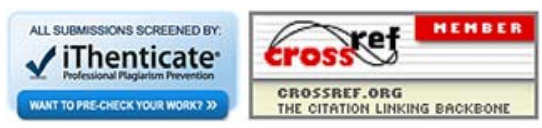


